\title{
Creciendo Sin: The Adaptation of the Unaccompanied Minors of the Mariel Boatlift
}

\author{
Kasey Crider \\ University of Miami, US \\ kc@miami.edu
}

\begin{abstract}
During the Mariel boatlift of 1980, roughly 2,000 unaccompanied refugee minors (URMs) arrived in South Florida without protection or parental supervision. These children were dispersed among camps in Wisconsin (Fort McCoy), Arkansas (Fort Chafee), and Pennsylvania (Fort Indiantown Gap) and were managed by voluntary agencies staffed with psychologists, physicians, educators and other professionals. Using oral histories from four of these staff members tasked with coordinating and executing the management of these unaccompanied children, the experience and subsequent adaptation outcomes of these URMs is evaluated. The personal testimonies are augmented with a review of the current literature surrounding the migrants of the Mariel boatlift and unaccompanied refugee minors, as well as an analysis of previously undocumented archival material. The unique challenge that faced the Mariel URMs is illuminated, and the likely negative adaptation outcomes are illustrated. Popular theoretical frameworks are applied to the Mariel case, including segmented assimilation theory and resiliency theory. The need for further study in the form of testimony from the Mariel URMs is demonstrated.
\end{abstract}

Keywords: unaccompanied refugee minors; Mariel Boatlift; migrant adaptation; Fort Indiantown Gap; Fort McCoy; VisionQuest

\section{Introduction}

Cuba's nuanced and complex history of migration to the United States has been extensively studied by sociologists for decades. Few events, especially those specific to children migrants, have been accounted for in the literature more than the unaccompanied refugee minors (URMs) of Operation Pedro Pan. ${ }^{1}$ The well-known and well-studied period of twenty months in the early 1960s saw roughly 14,000 children arrive in Miami without parents in an effort to escape the newly installed revolutionary government in Cuba. ${ }^{2} \mathrm{~A}$ collection of organizations (foremost the Catholic Church in South Florida) coordinated an effort to receive and assist the adaptation of these URMs to their new circumstances. ${ }^{3}$ Years later, a large number of these children achieved high levels of educational and professional attainment and have become an integral part of the thriving Cuban migrant community in Miami and across the US. ${ }^{4}$

However, there is another event involving unaccompanied Cuban children migrating to the US that seems to have been underrepresented in a body of more broadly focused research: the Mariel Boatlift. While research concerning the migrants of the Boatlift as a whole is plenty, there is comparatively little attention paid to the estimated 2,000 children that arrived without parents to South Florida two decades after the children of Operation Pedro Pan. ${ }^{5}$ More recent literature illustrates exacerbated vulnerabilities in URMs

\footnotetext{
${ }^{1}$ It is critical to clarify the use of the term "unaccompanied refugee minor" and its acronym in this essay. Current literature regarding unaccompanied migrant children is considerable and typically utilizes the URM label. As will be detailed in subsequent sections, the migrants of the Mariel Boatlift (including the unaccompanied minors) were not afforded the technical status of refugees, but instead given special status: Cuban-Haitian "entrant". In this study, I borrow the URM label to describe the circumstances of the children and not to match the label given by the US government at the time of migration.

2 See Bradford; Torres.

${ }^{3}$ See Walsh (1998).

${ }^{4}$ See Goyos.

${ }^{5}$ See Larzelere.
} 
while simultaneously suggesting potentially heightened resilience to challenge, ${ }^{6}$ indicating the need for a nuanced management response. As rapidly increasing numbers of URMs arrive in the US today, ${ }^{7}$ there is great value in exploring this group of now-adults at a quantitative and qualitative level.

This essay is an effort to bridge the gap in the current literature and analyze the experiences and adaptation outcomes of these children at a theoretical, empirical, and testimonial level. Oral history interviews were conducted with four people directly involved in the effort to receive and oversee these children upon arrival to the US. There is a rich base of oral histories for the URMs of Operation Pedro Pan and the people that assisted them, but very few from their Mariel counterparts. In subsequent sections, I detail the demographic profile of each oral history participant, explore relevant migration theory, and propose further direction of study.

\section{Historical Context}

According to a 1981 report from the American Public Welfare Association, nearly 125,000 Cubans arrived in Southern Florida for processing by the US Immigration and Naturalization Service in a six-month period spanning from April through October of $1980 .{ }^{8}$ A majority were sponsored by family members and released from the large processing compounds in a matter of days or weeks. However, for migrants who lacked immediate sponsors or featured significant complexities in their release, the federal government commissioned the establishment of additional sites meant for longer-term management: first, Eglin Air Force Base in Northern Florida and eventually Fort Chaffee (Arkansas), Fort McCoy (Wisconsin), and Fort Indiantown Gap (Pennsylvania). ${ }^{9}$ In the case of Fort Chafee, the camp was actually reestablished, following its use to oversee a group of Vietnamese refugees in $1975 .{ }^{10}$ Though verified numbers are difficult to find, websites for each of the three forts report significant numbers of migrants housed at the camps: Fort Chaffee-approx. 19,000; Fort McCoy-approx. 14,000; Fort Indiantown Gap-approx. 19,000. Responses from the oral history subjects roughly support these numbers for Fort Chaffee and Fort Indiantown Gap. Each of these long-term camps facilitated the management of migrants until the end of 1981.

Among the detainees in these long-term camps were a particularly vulnerable sub-group of approximately 2,000 URM's. ${ }^{11}$ These minors arrived in the US often having been expelled from Cuba, as explained below, and either did not have or were not aware of family that could sponsor their release. Though there was valuable insight to be gleaned from the management of Cuban URMs during Operation Pedro Pan, the haste required to respond to such a massive influx of refugees during the Mariel boatlift forced a more disjointed response. The initial 180 URMs in April and early May of 1980 were managed by the same Cuban Children's Program (CCP) that was established for the children of Operation Pedro Pan, thus the Mariel URMs were colloquially referred to as Operation Pedro Pan 2; the remaining arrivals were dispersed amongst the three refugee camps, a situation CCP director Monsignor Bryan Walsh called "a total disaster" (Walsh "Cultural Identity and Mental Health Factors Among Cuban Unaccompanied Minors").

The camps themselves were objectively challenging places for any child, and more so for those without parents, according to responses from the study subjects. Each camp was a military installation that featured barrack-style housing. The children were separated from the adult detainees by fences lined with barbed wire and patrolled by military police. Tensions in the camps were perpetually high, evidenced by the June 1, 1980 riot at Fort Chaffee that saw dozens of detainees and military police injured and the destruction of structures on the base via arson. ${ }^{12}$ The staff and detained children cycled constantly, making relationship development uniquely challenging. Additionally, uncertainty about the future likely caused distress and fear in the URMs.

It is also relevant to consider the broader sociopolitical context into which these refugees arrived. Both the city of Miami and the United States were experiencing a notable economic recession from 1980 to 1982. The Mariel migrants were widely stigmatized, though analysis reveals virtually no effect on native unemployment or wages due to the sudden influx of low skilled laborers from the Mariel boatlift. ${ }^{13}$ Additionally, much

\footnotetext{
6 See Huemer et al., Carlson et al., respectively.

7 See Kandel.

8 See Tans.

9 See Engstrom.

${ }^{10}$ See Lipman.

11 It should be noted that these estimates are contested and alternate sources suggest a total as low as 900. See Walsh (1981). Further study is required.

12 See Lipman.

${ }^{13}$ See Card. Though Card's seminal study has received considerable scrutiny and has been subject to multiple critiques, it has generally been accepted as the most relevant evidence of the Mariel Boatlift's effect on the Miami labor market.
} 
policymaking and media attention was paid to a growing concern with the illicit drug trade, often unfairly attributed to a problematically nondescript "Latin American" demographic, from which the Mariel migrants were not spared. ${ }^{14}$ Unfortunately, these stigmas endured, as they were "not mitigated by education, citizenship, English-language proficiency, or other experiences which would be expected to minimize the stigma of difference" (Fernández). Research conducted on the eventual adaptation by Cuban migrants prior to 1980 suggests generally positive outcomes, though the Mariel refugees seem to have suffered greater adaptation challenges than their predecessors, partly attributed to local and national stigma. ${ }^{15}$

\section{Methodology}

For this study, I examined the existing literature on URMs and on the adaptation of Mariel migrants as well as materials from the Carter Library and other relevant archives. Concurrently, semi-structured oral history interviews were conducted using four subjects. The oral histories were captured using the web-based video conferencing app, Zoom. Transcripts of the recordings were produced and authenticated by the authors. The subjects were chosen for their first-hand experience as staff members of the Cuban Adolescent Management Program (CAMP) at both Fort Chaffee and Fort Indiantown Gap. It is important to note that I made efforts to locate and include URMs of the Mariel boatlift as oral history subjects, but this proved exceedingly difficult and suggests a clear avenue to further enrich research on this topic in the future. Subjects were asked questions on four main topics: (1) their role in CAMP, (2) their own professional experience in CAMP, (3) their perception of the children's experiences at Fort Indiantown Gap, and (4) their perception of the adaptation outcomes of the children into adulthood. Each subject provided written permission to publish their responses and their identity in respect to those responses. The relevant biographical information for each subject is summarized below. The responses from the interview are integrated into the analysis in subsequent sections and augmented with reference to current literature and relevant archival materials.

Dr. José Szapocznik was the director of CAMP and operated primarily at Fort Chafee, though he oversaw the program managers at Fort Indiantown Gap as well. He was born in Havana, Cuba and migrated to the US in the 1960s when he was thirteen years old. He earned a bachelor's degree and a doctoral degree in clinical psychology from the University of Miami.

Dr. Carmen Díaz was a clinical psychologist at Fort Indiantown Gap. She was born in Havana, Cuba and migrated to the US during the Mariel boatlift in May 1980. She was quickly enlisted to help with CAMP due to her educational background-she was a Physics professor at the University of Havana until she was dismissed due to her homosexuality. She also offered the unique perspective of someone who experienced the boatlift as a participant and in the response to help her fellow refugees.

Dr. Raúl Hernández was a physician at Fort Indiantown Gap. He was born in Havana, Cuba and earned his degree and license to practice general medicine from the University of Havana. Like Dr. Díaz, he fled Cuba during the Mariel boatlift and was also solicited to provide his medical expertise to other detainees and eventually, the URMs.

Alberto Sarraín was a psychologist at Fort Indiantown Gap. He was born in Havana, Cuba and earned a degree in clinical psychology at the University of Havana. He had been incarcerated as a minor in Cuba for writing letters that suggested he was considering leaving the island. He was released at the age of 19 and came to the US in 1979, just prior the boatlift. He was quickly enlisted for his educational background and familiarity with Cuban cultural norms. His oral history was conducted in Spanish and, as such, his responses have been translated by the author.

\section{The Experience of the URMs}

To understand the experiences of the URMs in detention, it is helpful first to understand the demographic profile of the URMs. Little reliable data is available describing the URMs of Mariel-Szapocznik acknowledged that data collection was not systematic and what little data that might have been collected is unlikely to have been catalogued and maintained for future research purposes. The aforementioned discrepancy in a simple total count of URMs evidences the dearth of empirical figures. ${ }^{16}$

\footnotetext{
14 See Mohl.

15 See Portes et al., 1993; Portes et al., 2015.

16 There is a wealth of information regarding the Mariel boatlift housed at the Jimmy Carter Presidential Library in Atlanta, Georgia under the designation "Cuban-Haitian Task Force." Though few material labels in its finding aid are specific to unaccompanied minors, it is possible that verifiable data is available under more general categorization. Further research is required once the Carter Library reopens after the current closure related to the COVID-19 pandemic. Relevant microfilms of available material was assessed.
} 
However, a report compiled by the Children's Services Society of Wisconsin at Fort McCoy in Wisconsin did catalogue basic demographic information for 141 URMs that were detained there. 137 of the URMs were male $(97.2 \%)$. The average age was 17.6 years old, with the youngest URM being $14.56 \%$ of the teenagers had completed the seventh grade or lower, with only $11.3 \%$ having completed the $12^{\text {th }}$ grade. $82 \%$ of the URMs at Fort McCoy had been incarcerated in Cuba at some point, including nearly half of those for more than two years. Incarceration rates in Cuba need to be nuanced, as many of the Mariel refugees had been incarcerated for counter-revolutionary crimes in Cuba that would not be considered crimes in the US. Furthermore, Sarraín suggested that the very high concentration of previously incarcerated 16- and 17-yearolds could be a byproduct of the asymmetry between Cuban government's consideration of adulthood at 16 compared to 18 for the US, implying that the Cuban government would not classify these children as minors in the way the US did upon arrival. This suggestion is challenging to verify.

Finally, per an evaluation by the camp staff, 98.6\% of the detainees had an English language proficiency of "Poor/none." The report itself concludes that "the majority of Cuban minors who came to Wisconsin were unskilled, poorly educated males with no English skills. In addition, a large percentage of the youths had been institutionalized in Cuba." ${ }^{17}$

Race and sexuality are two additional critical demographic considerations that are even more poorly documented at a level specific to the URMs. There is no reliable data examining these factors, however a post-event evaluation of CAMP concluded that "a disproportionately high number (of the URMs at Fort Indiantown Gap) were 'black or mulatto"' (Szapocznik, 1985). It is unspecified in the report what the number was disproportionate to, and subsequent research demonstrates that there is little reason to believe that Mariel refugee population deviated from the island's racial composition. ${ }^{18}$ Further, Díaz asserted that "many of these kids-a much higher percentage than normal-were homosexual." While personal testimony is of great value, this is an area that undoubtedly demands further study.

There is also some debate regarding if the URMs migrated voluntarily or were forced by the Cuban government. The aforementioned Fort McCoy report documents that 32.6\% of the URMs under their supervision came to the US directly from prison, juvenile detention centers, or mental institutions in Cuba, and the Cuban Haitian Task Force reported similar findings, as $41 \%$ of all URMs surveyed reported being forced to migrate. Hernández suggested that these self-reported findings are likely dramatically skewed:

I don't think the kids felt permission to be honest, and remember, in an oppressive regime like Cuba's, anybody can be in prison for whatever reason. It's another tool of repression of the regime, so it doesn't tell you anything. It doesn't tell you about criminality.

Sarraín agreed with Hernández's implication that getting an accurate measure for the reasons behind the migration is challenging. He offered, "I remember (a boy) who was less than 16 years old who lived in Mariel. He started to swim and had gotten on a boat," indicating examples of those who chose to flee, as opposed to being forced.

The nature of the arrival to the camps likely had a negative impact on the refugees due to a lack of clarity on the process. As the majority of the Mariel refugees intended to be immediately united with family, the overarching understanding was that they were headed directly to Miami without delay, as expressed by both Mariel participants Díaz and Hernández. Díaz remembered:

When I realized that we were flying for more than an hour, I said, "Hmm, this is not Miami." Then what happened is that we passed by Three Mile Island (in Pennsylvania), the place where there was a big nuclear accident about a year before. I saw the nuclear reactors and said, "Oh my God, where are we?"

Sarraín indicated that there are probably behavioral consequences due to this misunderstanding:

They were flown to Pennsylvania not knowing they were going to Pennsylvania. They were not told, so most thought they were going to Miami. They then arrived at a military fort and were obligated to follow a military discipline to which they were not used. This provoked people to react in inappropriate or unexpected ways.

\footnotetext{
17 See Tans.

18 See Skop.
} 
These behavioral consequences ultimately manifested themselves in events such as the aforementioned Fort Chaffee riot. Though it is unclear if the URMs directly participated in any rioting, the volatility of camp conditions would suggest potentially adverse effects exacerbated by the lack of familial support. At times, it was not even safe for the staff, as Sarraín explained:

There was a lot of violence-a barrack for families with children, a barrack for women by themselves, a barrack for those who they suspected had come from jails in Cuba, another for those with mental issues, and a barrack for unaccompanied minors. The situation became volatile and one day, they pulled us out of the camp and apparently there were riots. I don't know exactly what happened, but it could not have been good.

Szapocznik noted the negative impact this fear had on the young men, saying, "The cots in which they slept had metal slats under the mattress. They would tear out a metal slat and make a machete out of it. They felt they needed protection because they were used to being in places where they had to protect themselves."

Initially, the timeline for release from the camp was not clear to the staff or the URMs. The chaotic nature of the design and implementation of these programs in real time contributed to anxiety. Funding, staffing, and organizational structures had to be adapted daily, creating instability for the young Cubans, particularly those who had arrived earliest. Hernández emphasized:

The kids were totally overwhelmed. They were afraid. They were totally uncertain about what was going to happen-we didn't know what was going to happen! No one knew what was going to happen. We didn't know how long they were going to be there. There was no resettlement at the time. It was not clear who had the legal guardianship. The agencies were not ready to deal with them. ${ }^{19}$

After the initial uncertainty subsided and some routine was established, the goal of both the URMs and the staff shifted. The objective of CAMP was twofold: to expedite the resettlement of these youths as safely as possible and to study the effects of this refugee crisis and displacement on adolescents. The program received only marginal support and consideration from governmental organizations; as only an estimated one percent of the total refugee count, resources and attention were directed to subjectively more pressing concerns, leaving Szapocznik and his group to largely fend for themselves. Furthermore, feelings of fear and anxiety gave way to despair and depression the longer the URMs remained at the camps. This was likely intensified by a complex legal status that befell all the Mariel migrants due to implicit procedural avoidance of the recent Refugee Act of 1980 in favor of a special "entrant" bureaucratic classification, in addition to incoherent determinations of custody for the URMs. ${ }^{20}$ According to the Cuban/Haitian Entrant Program Operating Manual, the URMs of Mariel were "eligible for benefits comparable to those available to refugee unaccompanied minors as set forth by the Refugee Act of 1980"; the phrasing demonstrates the complicated intentional delineation between the Mariel migrants and defined refugees. ${ }^{21}$

A unique and significantly understudied feature of CAMP specific to Fort Indiantown Gap was the use of a behavioral rehabilitation group known as VisionQuest. Among many interventional methods, the program entailed placement "in rustic wilderness camps, then on the road in wagon trains" (Greenwood et al.). Although it is unclear the extent to which the Mariel URMs participated in the various aspect of the program, Díaz recalled some of these methods, saying, "[VisionQuest] put the kids in very difficult situations with horses, having to walk long distances through the mountains, these types of things."

The assessment from each of the oral history subjects regarding VisionQuest was conflicting. The program employed controversial methods centered on intense direct confrontation between the program staff and youths that may last for up to 30 minutes, involving physical restraint and aggressive, loud verbal interaction. ${ }^{22}$ In the view of some of the staff, this was ineffective and inhumane, exacerbating language issues and causing further distress in the URMs. Hernández believed the practice to be so inappropriate, he briefly quit his position, along with a number of colleagues:

\footnotetext{
${ }^{19}$ It is unclear if Hernández was referring to state/US governmental agencies (such as the foster care system) or private organizations.

${ }^{20}$ See Engstrom; Bon Tempo.

${ }^{21}$ See Carosso.

${ }^{22}$ See Greenwood et al.
} 
(The VisionQuest staff) gave us a couple of demonstrations of their techniques, and we were horrified. They would start talking to the kids and suddenly start screaming at them in their face. They grabbed (the kids) and threw them on the ground and climbed on top of them, screaming at the top of their lungs, "This is what you need to do!" We were horrified-we thought it was child abuse. We thought it was untenable and we went to directors and decision makers and said, "We don't think this is right." We were told that (we should) accept it because this was it. (We needed) to come on board. A number of us wouldn't take it and resigned and left. I was one of them ... Something must have really happened because about a week-ten days-later, I personally got word that they decided that VisionQuest was not a good fit and they were leaving. They said, "If you want, you can come back because we need you." So almost all of us came back.

As the person who contracted VisionQuest, Szapocznik had a more measured and optimistic perspective:

There was a very good program that I was familiar with-VisionQuest. One of the things they did when a child was out of control in that program is these very big men would sort of lay on them and hold them down on the ground until they had calmed down. And I just needed that for the safety of the other children.

VisionQuest continued its use of these controversial methods for a number of years following CAMP, most notably via contract with juvenile corrections departments in San Diego and Philadelphia. Although the confrontation methods were eventually modified and subsequently abandoned, it seems the URMs at Fort Indiantown Gap were subjected to these physical and verbal intervention techniques. After significant modifications to its curriculum, the program still operates today, focusing on Functional Family Therapy.

\section{The Adaptation of the Mariel URMs in Adulthood}

Each oral history subject acknowledged (and lamented) that they had not kept track of any of the URMs with whom they had interacted at Fort Chaffee and Fort Indiantown Gap. Programs such as CAMP were tasked with receiving the children and resettling them in less temporary circumstances such as orphanages and foster homes. This transition is poorly documented and the oral history subjects were unfamiliar with the initial stages of integration into mainstream society. This speaks to a broader absence in the literature detailing the adaptation outcomes in adulthood. However, there are some potentially useful comparisons and theoretical considerations to be made, in addition to a number of areas of future exploration.

As previously mentioned, the stigma of the "Marielitos" had undeniable negative consequences. While many Mariel refugees have adapted positively, there is evidence for higher rates of incarceration relative to non-Mariel Cuban migrants, irrespective of other positive social and demographic indicators. ${ }^{23}$ Furthermore, there is evidence that URMs are at elevated risk for mental health issues and negative adaptation outcomes. ${ }^{24}$ This is complicated by the aforementioned evidence that many of the Mariel URMs arrived with mental health concerns, making it difficult to establish appropriate correlations. This contrasts significantly with the outcomes experienced by Cuban migrant children with parents, who enjoy some of the most positive economic outcomes of all migrant groups. ${ }^{25}$ Thus, similar research documenting non-Cuban URMs is likely insufficient to capture the reality of adaptation of the URMs of Mariel, and better understanding can potentially be gained from personal testimony and more targeted empirical evidence.

As part of their experience in the detention camps, there were some limited attempts to equip the URMs for their eventual entry into US society. The transient nature of the personnel and children made sustainable, coherent efforts challenging, but the English language was introduced in a classroom setting in small doses. Szapocznik readily acknowledged these challenges:

In the camps, we didn't try to help them assimilate. But we did try to teach them English-part of their studies was learning English. But the culture they were living in was so Hispanic-everybody was Hispanic around them-and you partly acculturate by coming into contact with the culture that receives you. That wasn't happening much when they were in the camps.

\footnotetext{
23 See Aguirre et al.

${ }^{24}$ See Carlson.

25 See Potocky.
} 
There is some evidence that the URMs collaborated with management staff to make their transition as positive as possible: an August 19, 1980 edition of the Fort McCoy newspaper El Mercurio de McCoydocumented a committee of five boys who were charged with organizing their experiences through sports, food, and basic education. However, the unique challenge for the URMs is that they typically did not have a receiving family to buffer their adaptation, even when they left the camps. Further, relevant research in second-language acquisition would suggest that the Mariel URMs likely faced a significant barrier outside of Spanishspeaking communities. $^{26}$

It might also be useful to consider potential adaptation outcomes from a theoretical perspective. Broadly speaking, Alejandro Portes' segmented assimilation theory provides a lens through which the URMs of Mariel can be assessed. Segmented assimilation theory suggests that the primary indicators of positive adaptation are correlated to immediate circumstances surrounding the migrant, both at departure and upon arrival. Common factors include the professional and educational attainment of immediate family members (particularly parents), as well as rates of incarceration. ${ }^{27}$ It is critical to note that Portes' work is quantitatively driven, making the lack of verified data detailing the URMs of Mariel difficult to compare. However, if segmented assimilation theory is applied, the reported challenging personal, social, academic, and criminal circumstances associated with these URMs likely suggest significant adaptation challenges.

José Goyos' use of resiliency theory to explain the often-positive adaptation outcomes of the children of Operation Pedro Pan is another useful theoretical line of analysis. While traditional psychoanalytic and child development theory would suggest negative outcomes from the trauma of unaccompanied migration, Goyos identifies three resiliency factors in the OPP children that explain positive adaptations: educational and economic background, personal characteristics, and self-perception of experience (Goyos). Clearly, the second and third factors are impossible to assess without personal testimonies from the URMs themselves; however, the narratives provided by the oral history subjects and relevant data support less-than-ideal educational and economic circumstances surrounding the URMs, again suggesting negative adaptation outcomes. Sarraín's perspective paralleled this conclusion, as he acknowledged, "Most of the unaccompanied minors had not finished school, had a hard life and had been fending for themselves, facing life as adults [in Cuba]."

Ultimately, none of the oral history subjects were particularly optimistic about potential adaptation outcomes of the Mariel URMs. Díaz understood that her professional skillset and strong English skills made her path to positive adaptation comparatively more manageable:

I don't want to imagine what happened to (those kids). Because I was armed. I had something to sell. Because I was a physicist. But these (kids) have nothing. How are they going to manage?

CAMP likely played a role in the unknown adaptation outcomes, both positively and negatively, as Hernández asserted:

It would be presumptuous on my part to say it was wonderful and they really assimilated well-no. We did the best we could under the circumstances ... It was a matter of learning as we went along. And there were a lot of mistakes ... I would say we did a good job. It could have been absolutely miles better than what we did, but we had to work with what we had which was not much-some funding and a great deal of dedication by the staff working there.

\section{Conclusion}

This project is multipurpose. First, it fills a gap in the current literature base by adding the personal testimonies of several people who worked closely with the URMs of Mariel to illuminate and preserve the work of CAMP, which is currently sparsely documented. Second, it brings to light the existence of archival documents which have not previously been considered. Third, it augments the literature on URM management and policy by demonstrating the successes and failures of CAMP. Finally, as the number of URMs increase in the US, a better understanding of previous successes and failures in dealing with the URMs from Mariel suggests that, in order to be effective, coordinated responses to URMs' situations in the short and long term is paramount.

There are numerous areas demanding further study. Quantitative data documenting the URMs is necessary to better assess demographics. Further, research directly engaging the URMs themselves is critical. Much of

\footnotetext{
${ }^{26}$ See Eisenstein; Pica.

${ }^{27}$ See Xie et al.
} 
this project is based on perception via personal testimony and theoretical assumptions and extrapolations. Undoubtedly, the voices of the actual participants would be most valuable. These efforts would likely be quite challenging, but both doable and fruitful.

The Mariel Boatlift was a life-defining event for both the refugees involved and those that assisted them. The unaccompanied minors are an underrepresented piece of the Mariel story and studying the perspectives of those tasked with facilitating their positive adaptation to the US is a critical step toward understanding and celebrating that piece of the story.

\section{Competing Interests}

The author has no competing interests to declare.

\section{References}

Aguirre, Benigno E., Rogelio Saenz, and Brian Sinclair James. "Marielitos Ten Years Later: The Scarface Legacy." Social Science Quarterly, 1997, pp. 487-507.

Bon Tempo, Carl J. Americans at the Gate: The United States and Refugees During the Cold War. Princeton University Press, 2008. DOI: https://doi.org/10.1515/9781400829033

Bradford, Anita Casavantes. "Remembering Pedro Pan: Childhood and Collective Memory Making in Havana and Miami, 1960-2000." Cuban Studies, 2016, pp. 283-308. DOI: https://doi.org/10.1353/cub. 2016.0011

Card, David. "The Impact of the Mariel Boatlift on the Miami Labor Market." ILR Review, vol. 43, no. 2, 1990, pp. 245-257. DOI: https://doi.org/10.1177/001979399004300205

Carlson, Bonnie E., Joanne Cacciatore, and Barbara Klimek. "A Risk and Resilience Perspective on Unaccompanied Refugee Minors." Social Work, vol. 57, no. 3, 2012, pp. 259-269. DOI: https://doi. org/10.1093/sw/sws003

Carosso, Juan. Cuban/Haitian Entrant Program Operating Manual. Cuban/Haitian Task Force (DHHS), Washington, D.C. 20 Mar. 1981.

Díaz, Carmen. "Carmen Díaz oral history interview conducted by Lulwah Aldamkhi in Miami, Florida, 2020-11-18."

Eisenstein, Miriam. "A Study of Social Variation in Adult Second Language Acquisition." Language Learning, vol. 32, no. 2, 1982, pp. 367-391. DOI: https://doi.org/10.1111/j.1467-1770.1982.tb00977.x

Engstrom, David Wells. Presidential Decision Making Adrift: The Carter Administration and the Mariel Boatlift. Rowman \& Littlefield, 1997. DOI: https://doi.org/10.1111/j.1747-7379.2007.00087.x

Fernández, Gastón A. "Race, Gender, and Class in the Persistence of the Mariel Stigma Twenty Years After the Exodus from Cuba." International Migration Review, vol. 41, no. 3, 2007, pp. 602-622.

Goyos, José Manuel. "Identifying Resiliency Factors in the Adult 'Pedro Pan' Children: A Retrospective Study." Barry University School of Social Work, 1996.

Greenwood, Peter W. and Susan Turner. The VisionQuest Program: An Evaluation. The Rand Corporation, 1987.

Hernández, Raúl. "Raúl Hernández oral history interview conducted by Kasey Crider in Miami, Florida, 2020-12-02."

Huemer, Julia, et al. "Mental Health Issues in Unaccompanied Refugee Minors." Child and Adolescent Psychiatry and Mental Health, vol. 3, no. 1, 2009, pp. 1-10. DOI: https://doi.org/10.1186/1753-2000-3-13

Kandel, William A. "Unaccompanied Alien Children: An Overview." Congressional Research Service 43599, 2017.

Larzelere, Alex. Castro's Ploy - America's Dilemma: The 1980 Cuban Boatlift. National Defense University Press, 1988.

Lipman, Jana K. "A Refugee Camp in America: Fort Chaffee and Vietnamese and Cuban Refugees, 19751982." Journal of American Ethnic History, vol. 33, no. 2, 2014, pp. 57-87. DOI: https://doi.org/10.5406/ jamerethnhist.33.2.0057

Mohl, Raymond A. "Changing Economic Patterns in the Miami Metropolitan Area, 1940-1980." Tequesta, vol. 1, 1982, pp. 63-73.

Pica, Teresa. "Adult Acquisition of English as a Second Language under Different Conditions of Exposure." Language Learning, vol. 33, no. 4, 1983, pp. 465-497. DOI: https://doi.org/10.1111/j.1467-1770.1983.tb00945.x

Portes, Alejandro, and Aaron Puhrmann. "A Bifurcated Enclave: The Economic Evolution of the Cuban and Cuban American Population of Metropolitan Miami." Cuban Studies, 2015, pp. 40-63. DOI: https://doi. org/10.1353/cub.2015.0010 
Portes, Alejandro, and Alex Stepick. City on the Edge: The Transformation of Miami. Univ of California Press, 1993.

Potocky, Miriam. "Refugee Children: How Are They Faring Economically As Adults?." Social Work, vol. 41, no. 4, 1996, pp. 364-373.

Sarraín, Alberto. "Alberto Sarraín oral history interview" conducted by Kasey Crider in Miami, Florida, 2020-11-19."

Skop, Emily H. "Race and Place in the Adaptation of Mariel Exiles." International Migration Review, vol. 35, no. 2, 2001, pp. 449-471. DOI: https://doi.org/10.1111/j.1747-7379.2001.tb00025.x

Szapocznik, José. "José Szapocznik oral history interview conducted by Kasey Crider in Miami, Florida, 2020-12-07."

Szapocznik, José, Raquel E. Cohen, and Roberto E. Hernández. Coping with Adolescent Refugees: The Mariel Boatlift. Praeger, 1985.

Tans, Elizabeth Jane. "Cuban Unaccompanied Minors Program: The Wisconsin Experience." Child Welfare, vol. 62, no. 3, 1983.

Torres, María de los Angeles. The Lost Apple: Operation Pedro Pan, Cuban children in the US, and the Promise of a Better Future. Beacon Press, 2004.

Walsh, Monsignor Bryan O. "Bryan O Monsignor Walsh oral history interview conducted in Barry University, Miami, Florida, 1998-12-03."

Walsh, Monsignor Bryan O. "Cultural Identity and Mental Health Factors Among Cuban Unaccompanied Minors." Digital Library of the Caribbean, Barry University, 1981.

Xie, Yu, and Emily Greenman. "Segmented Assimilation Theory: A Reformulation and Empirical Test." Population Studies Center Research Report 05-581, 2005.

"Youths Elect Advisory Council." El Mercurio de McCoy, August 19, 1980. Available at digitalcollections. uwlax.edu/jsp/RcWebImageViewer.jsp?doc_id=e48a5846-c692-42e4-943e-4e7281f34d77/wlacu000/ 00000017/00000282\&pg_seq=1\&search_doc=. Accessed April 20, 2021.

How to cite this article: Crider, K 2021 Creciendo Sin: The Adaptation of the Unaccompanied Minors of the Marie Boatlift. Anthurium, 17(2): 16, 1-9. DOI: https://doi.org/10.33596/anth.442

Published: 14 December 2021

Copyright: (c) 2021 The Author(s). This is an open-access article distributed under the terms of the Creative Commons Attribution 4.0 International License (CC-BY 4.0), which permits unrestricted use, distribution, and reproduction in any medium, provided the original author and source are credited. See http://creativecommons.org/licenses/by/4.0/. 